Artvin Çoruh Üniversitesi

Orman Fakültesi Dergisi

ISSN:2146-1880, e-ISSN: 2146-698X

Yıl: 2018, Cilt: 19, Sayı:2, Sayfa:144-153

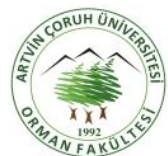

fd.artvin.edu.tr

(c) (i)
Artvin Coruh University

Journal of Forestry Faculty

ISSN:2146-1880, e-ISSN: 2146-698X

Year: 2018, Vol: 19, Issue: 2, Pages:144-153

\title{
Mobilya köşe birleştirmelerinde demonte tipi bağlantı elemanlarının moment kapasitesine etkileri
}

\section{The effects of disassembled type connection elements moment capacity in furniture corner joints}

\author{
Abdurrahman KARAMAN ${ }^{1}$, Mehmet Nuri YILDIRIM², Recep AYKAN ${ }^{3}$ \\ 'Uşak Üniversitesi Banaz Meslek Yüksek Okulu Uşak, Türkiye \\ ${ }^{2}$ Karabük Üniversitesi Safranbolu Meslek Yüksek Okulu Karabük, Türkiye \\ ${ }^{3}$ Sinop Üniversitesi, Ayancık Meslek Yüksek Okulu Sinop, Türkiye
}

Eser Bilgisi / Article Info

Araştırma makalesi / Research article

DOI: $10.17474 /$ artvinofd.409500

Sorumlu yazar / Corresponding author Mehmet Nuri YILDIRIM

e-mail: emnyildirim@karabuk.edu.tr

ORCID: 0000-0002-0180-4479

Geliş tarihi / Received

26.03.2018

Düzeltme tarihi / Received in revised form

05.10.2018

Elektronik erişim / Online available

22.10.2018

Anahtar kelimeler:

Ahşap kompozit malzeme

Köşe birleştirme

Metal T bağlantı elemanı

Ay bağlantı elemanı

Plastik T bağlantı

Keywords:

Wood composite material

Corner joint

Metal T connector

Connector Fitting

Plastic T connector

\begin{abstract}
Özet
Bu çalışmada, mobilya köşe birleştirmelerinde kullanılan demonte tipi bağlantı elemanlarının moment kapasitesine etkileri araştırımıştır. Deney örnekleri ahşap esaslı kompozit levhalardan, sentetik reçinelerle kaplanmış yonga levha (YL-Lam) ve lif levhalardan (MDF-Lam) hazırlanmıştır. Bağlantı elemanı olarak metal $L$, plastik $T$, metal $T$ ve ay bağlantı elemanı olmak üzere dört farklı bağlantı elemanı kullanılmıştır. Deney örnekleri, kullanımları sırasında etkisinde kalabilecekleri kritik yükler göz önüne alınarak statik yük altında basma ve çekme deneyine tabi tutulmuştur. Deney sonuçlarına göre, diyagonal basma deneyinde moment taşıma kapasitesi değeri; bağlantı elemanı çeşidine göre en yüksek değer, metal L bağlantı elemanı ile birleştirilen deney örneklerinde, en düşük değer ise $A y$ bağlantı elemanında tespit edilmiştir. Ahşap esaslı kompozit levha-bağlantı elemanı tipi ikili etkileşimlerindeki diyagonal çekmede, en yüksek değer MDF-Lam ile metal $L$ bağlantı elemanı hazırlanan deney örneklerinde, en düşük değer ise YL-Lam ile ay bağlantı elemanı ile hazırlanan örneklerde tespit edilmiştir Bu veriler ışığında, mobilya elemanları köşe birleştirmelerinde MDF-Lam malzemesi ile metal L bağlantı elemanı kombinasyonu uygulanabilir.
\end{abstract}

\begin{abstract}
In this study, the effects on the moment capacity of demountable fasteners used in furniture corner joints were investigated. Experimental specimens were prepared from wood based composite boards, synthetic resin coated particle board (YL-Lam) and fibre boards (MDF-Lam). Four different types of fasteners (metal $\mathrm{L}$, plastic $\mathrm{T}$, metal $\mathrm{T}$ and corner fitting) were used. The test specimens were subjected to compression and tensile testing under static loads, taking into account the critical loads that they could experience under their use. According to the test results, the diagonal compression test moment carrying capacity value; the highest value for the type of fasteners was observed in the test samples combined with the metal $L$ connector, while the lowest value was determined in the test samples combined with the corner fitting. In the diagonal tension of wood-based composite boardconnector element type interaction; the highest value was determined in the samples prepared MDFLam with the metal $L$ connector, while the lowest value was observed in the test samples prepared YL-Lam with the corner fitting. In the light of these data, the combination of MDF-Lam with metal L connector can be applied to the furniture elements corner joints.
\end{abstract}

\section{GíRiş}

Mobilya köşe noktaları mobilyanın dayanımı açısında önem arz etmektedir. Mobilya köşe birleştirmelerinde farklı bağlantı elemanları kullanılmaktadır. Kullanılan bağlantı elemanlarının etkisinde kalacağı yüklere karşı nasıl bir davranış göstereceği belirlenmesi mobilya mukavemeti açısında önemlidir. Bu önemden yola çıkarak yapmış olduğumuz bu çalışmada, mobilya köşe birleştirmelerinde kullanılan demonte tipi bağlantı elemanlarının moment kapasitesine etkileri araştırılmıştır.
Yapılan araştırmalarda mobilya elemanlarının kullanım yerinde üzerinde oluşan yükler sonucunda deformasyonların olduğunu bildirmişlerdir. Konut veya işyerlerinde kullanılan mobilyalar kullanım amacına bağlı olarak çeşitli mekanik zorlamalar ile karşı karşıya kalmaktadır. Bu zorlamalarda, etkili olan kuvvetin şekli ve şiddetine göre mobilya elemanlarının birleşme yerlerinde açılma ve gevşeme, elemanlarda eğilme, çatlama veya kırılma gibi deformasyonlar meydana gelir. Sağlamlık ve kaliteyi doğrudan etkileyen deformasyonların büyüklüğü, birleşme yerlerinde uygulanan konstrüksiyona, yapıştırıcı ve ağaç malzeme türüne göre değişmektedir (Altınok 1998; Efe ve Kasal 2000a; Taştekin ve Özyurt 2001). 
Mobilya üretiminde malzemelerin, fiziksel ve mekaniksel etkilere karşı davranış biçimlerinin önceden bilinmesi, tasarımcı, üretici ve kullanıcılara teknik, estetik ve ekonomik yararlar sağlamaktadır. Gerek tasarım gerekse buna dayalı bilimsel çalışmalarda; malzemenin fiziksel ve mekanik özellikleri ile birleştirmelerinin dirençlerine ait veriler kullanıldığını bildirmişlerdir (Efe 1994).

Mobilyada meydana gelen bu deformasyonların en aza indirilmesi için, tasarım ve üretim sürecinde çeşitli konstrüksiyonlar uygulanmaktadır (Efe ve Kasal 2000a).Mobilya elemanlarının birbirine bağlanmasında kavelalı ve zıvanalı birleştirme gibi geleneksel tekniklerin yanında, konut veya ofislerde monte edilen ve kullanımı hızla yaygınlaşmakta olan demonte (Ready- To- Asemble) mobilyalar; modern mobilyanın bir stili olan demonte mobilya, tüketici veya satıcı tarafından tüketicinin kullanım yerinde iş parçalarını bir araya getirilip monteye hazır olarak tasarlanan, istenildiğinde sökülüp tekrar başka mekanda kullanılmak üzere iş parçalarının paketlenerek nakledilmesi ile oluşturulan tüketim mallarıdır. Sökülüp-takılabilir birleştirme tekniklerinin uygulandığı mobilyalar portatif olduğundan, bunların montajı müşterinin istediği yerde yapılabilir. Böylece nakliye maliyetleri azaltılmış olur. Bu mobilyalar sökülmüş vaziyette depolandığı takdirde, sabit mobilyalara nazaran daha az yer kaplarlar. Bu durum imalatçılar ve satıcılar açısından oldukça önemlidir. Demonte birleştirmeler sağlamış olduğu bu üstünlükler nedeniyle tercih edilmektedirler Mobilya elemanlarının birbirine bağlanmasında geleneksel yöntemler (kavelalı, zıvanalı birleştirme v.b.) yanında, ofis ve konutlarda monte edilen ve kullanımı hızla yaygınlaşan demonte mobilyaların konstrüksiyonunda metal veya metal+plastikten üretilen mekanik bağlantı elemanları kullanıldığını bildirmişlerdir (Hayashi and Eckelman 1986; Trinka 1989; Kasal 1998).

Metal konstrüksiyonlu trapez bağlantı demonte birleştirmelerin direnç özelliklerini araştırmışlardır. Çalışmalarında mekanik bağlantı elemanlarının avantajlarından bahsetmişlerdir (Smardzweski et al. 2002). Farklı RTA (Ready To Assembly) birleştirme elemanlarının kullanıldığı köşe birleştirmelerinde en yüksek direnç MDF'de kullanılan metal trapezlerde elde edilirken, en düşük dirençler yonga levhada kullanılan rafixlerde elde edilmiştir (Tankut 2006).

Minifiks, kavela ve farklı köşe birleştirme tiplerinin diyagonal çekme direnci üzerine etkilerini araştırmışlardır. En yüksek diyagonal çekme direncini, MDF Lamdan yapılmış alyans vidalı birleştirmelerden elde etmişlerdir (Güray vd. 2002), Kutu mobilyalarda bazı modüler bağlantı elemanları ile yapılan köşe birleştirmelerin diyagonal basma ve çekme dirençlerini belirlemek amacıyla yapılan çalışma sonucunda; en iyi sonucun doğu kayını ile çift çektirmeli bağlantı elemanın kullanılarak hazırlanan deney örneklerinde tespit etmişlerdir (Kılıçalp 2007; Özçifçi vd. 2008).

Yapılan bir çalışmada deneylerde çekme direnci, basma direncinden yüksek çıkmıştır. Toplam çekme direnci basma direncinden \%49,3 daha yüksektir. En yüksek basma direnci plastik ' $L$ ' birleştirme elemanı ile en düşük basma direnci ise minifiks birleştirme elemanı ile elde edilmiştir. Diyagonal çekme deneylerinde bağlantı elemanı çeşidi bakımından en yüksek çekme direnci eğri metal ' $T$ ' çektirme bağlantı elemanında elde edilmiştir. En düşük çekme direnci minifiks ile yapılan birleştirmeden elde edilmiştir. Eğri metal ' $T$ ' çektirme bağlantı elemanının yüksek çekme direnci göstermesinin sebebi, diğer birleştirmelere göre ahşap malzemeye tutunma yüzey alanlarının daha fazla olması olabilir (Karabulut 2010).

Literatürde kutu konstrüksiyonlu mobilya üretiminde kullanılan köşe birleştirmelerden; tutkallı (sabit) ve tutkalsız (demonte) birleştirmelerin çekme ve basma direnci üzerine birçok çalışmada, lif levhalar, yonga levhalardan ayrıca tutkalsız (demonte) birleştirmeler, tutkallı (sabit) birleştirmelerden daha iyi sonuçlar vermişlerdir (Efe 1994; Örs ve Efe 1996; Örs ve Efe 1998; Kasal 1998; Efe 1999; Efe ve Kasal 2000a; Efe ve Kasal 2000b; İmirzi 2000; Şafak 2000; Efe 2001; Efe ve İmirzi 2001; Efe vd. 2002; Efe vd. 2003; Kasal vd. 2006, Şakacı 2010; Tüfekli 2010; Efe vd. 2012), multifix bağlantı elemanlarının minifix bağlantı elemanlarına göre daha başarılı olduğunubelirtmişlerdir (Efe ve Kasal 2000b), en iyi sonucu tutkalsı multifixli köşe birleştirmeler verdiğini bildirmiştir (Şafak 2000), demonte birleştirmelerden 
trapez köşe birleştirmenin diğer birleştirme çeşitlerine göre daha yüksek performans gösterdiği tespit edilmiştir (Şakacı 2010),kutu konstrüksiyonlu demonte mobilya üretiminde, bağlantı elemanı olarak minifix bağlantı elemanın (Tüfekli 2010), trapez+kavelalı birleştirme kullanılmasının ürünün performansı artırdığııı bildirmişlerdir (Demirci vd. 2011).

Bu çalışmada, ahşap esaslı malzemelerden (MDF-Lam, YLLam) ile demonte tipi bağlantı elemanları kullanılarak hazırlanan L tipi köşe birleştirmelerin diyagonal çekme ve basma deneyleri sonucu elde edilen eğilme moment değerleri araştırılmıştır.

\section{MATERYAL VE YÖNTEM}

\section{Materyal}

Deney örneklerinin hazırlanmasında malzeme olarak; TS EN 312-2 esaslarına uygun üretilmiş, $18 \mathrm{~mm}$ kalınlığında sentetik reçinelerle kaplanmış yonga levha (YL-Lam) ve TS 64-3 EN 622-3 esaslarına uygun üretilmiş, $18 \mathrm{~mm}$ kalınlığında sentetik reçinelerle kaplanmış orta sert Lif Levha (Medium Density Fiberboard Laminasyon: MDFLam), Deneylerde kullanılan ahşap malzemelerin bazı fiziksel ve mekanik özellikleri Çizelge 1'de verilmiştir.

Çizelge 1Ahşap esaslı levhalarınbazı fiziksel(\%), $\left(\mathrm{gr} / \mathrm{cm}^{3}\right)$, ve mekanik özellikleri(N/mm²).

\begin{tabular}{lllll}
\hline Malzeme & Rutubet & Yoğunluk & E. Gerilmesi & E. Modülü \\
\hline YL-Lam & 6.51 & 0.69 & 15.00 & 4435 \\
MDF-Lam & 5.93 & 0.78 & 26.91 & 4347 \\
\hline
\end{tabular}

Mobilya köşe birleştirmelerinde kullanılan demonte tipi bağlantı elemanları Şekil 1- 4 arasında gösterilmiştir. Ölçüler mm cinsindedir.

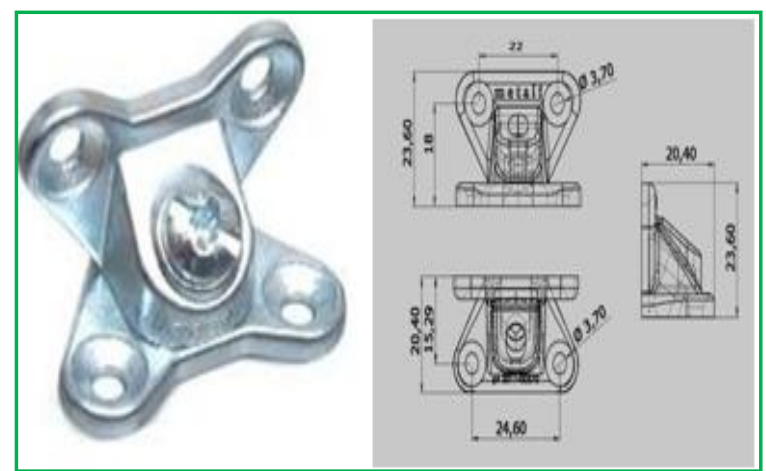

Şekil 1Metal T bağlantı elemanı.

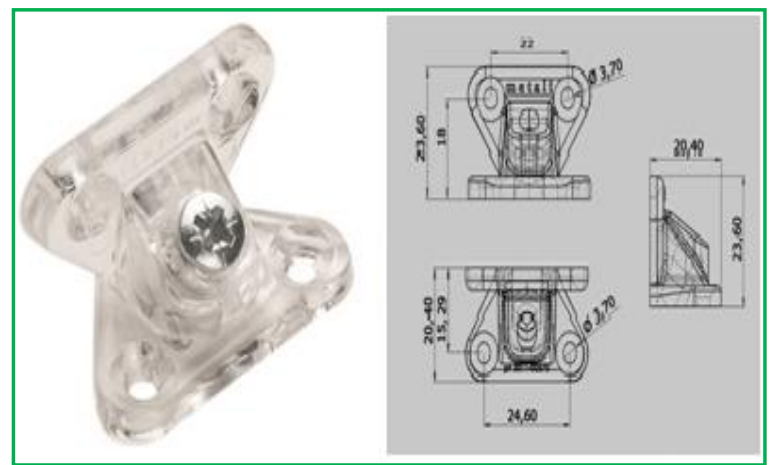

Şekil 2 Plastik T bağlantı elemanı.

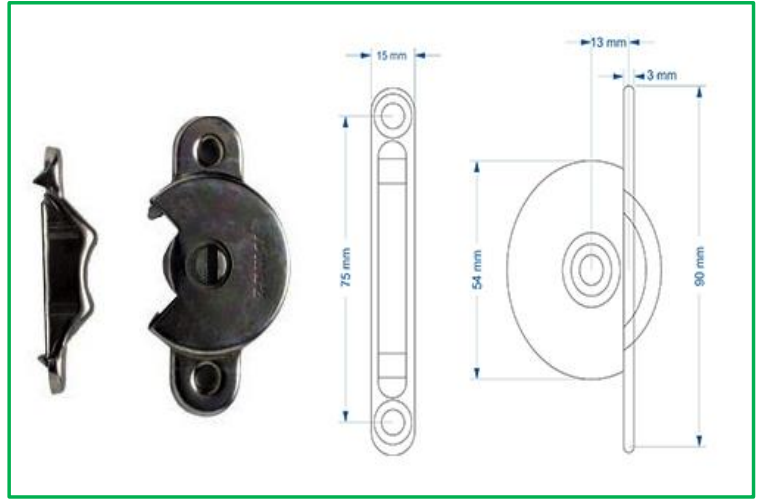

Şekil 3Ay bağlantı elemanı.

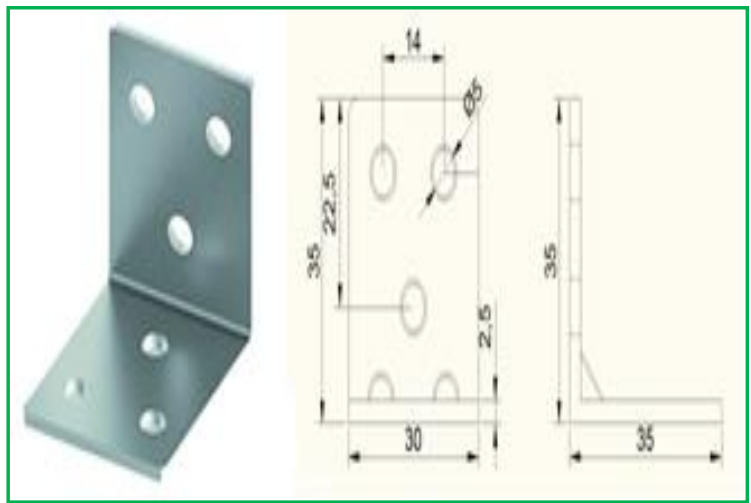

Şekil 4 Metal L bağlantı elemanı.

Deney örneklerinin diyagonal çekme ve basma yükleri altındaki moment taşıma kapasitelerinin belirlenmesi ile ilgili bir standart olmadığından daha önceden yapılmış çalışmalardaki deney örneklerinden yararlanılmıştır. (Örs vd. 2001; Efe vd. 2003; Kasal vd. 2006; Kasal 2008). Her bir deney örneği kenar ve yüzey olmak üzere iki 
elemandan oluşmaktadır. Kenar elemanı 270 x $132 \mathrm{~mm}$, yüzey elemanı ise $270 \times 150$ mm ölçülerindedir.

$A$ ve $B$ elemanlarının yüzeyine uzun kenarından $5 \mathrm{~mm}$ içeriden, kısa kenarından ise $50 \mathrm{~mm}$ içeriden simetri olacak şekilde 2 bağlantı elemanı 8 adet $3.5 \times 18$ vida ile monte edilerek $L$ tipi deney örnekleri hazırlanmıştır. Deneylerde " $\mathrm{L}$ " biçiminde hazırlanan örneklerin genel görünüşü ve birleşme yerlerinin detayı Şekil 5' deki gibidir.

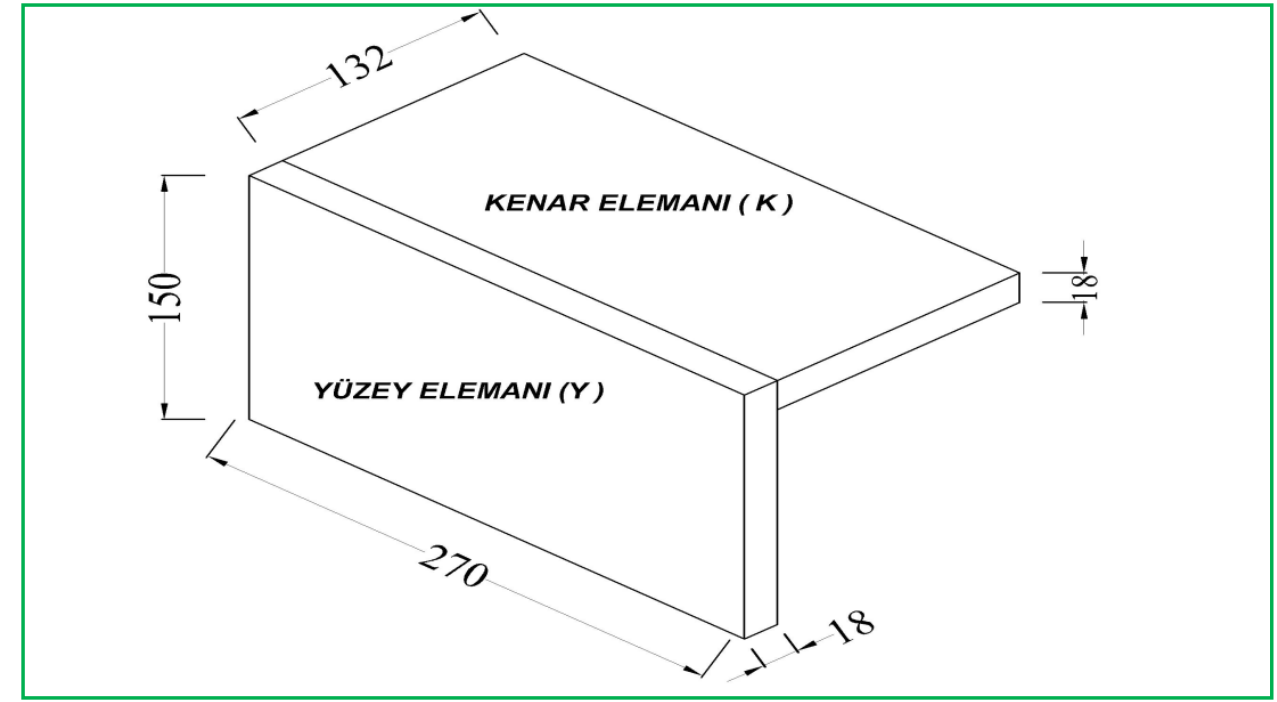

(a)

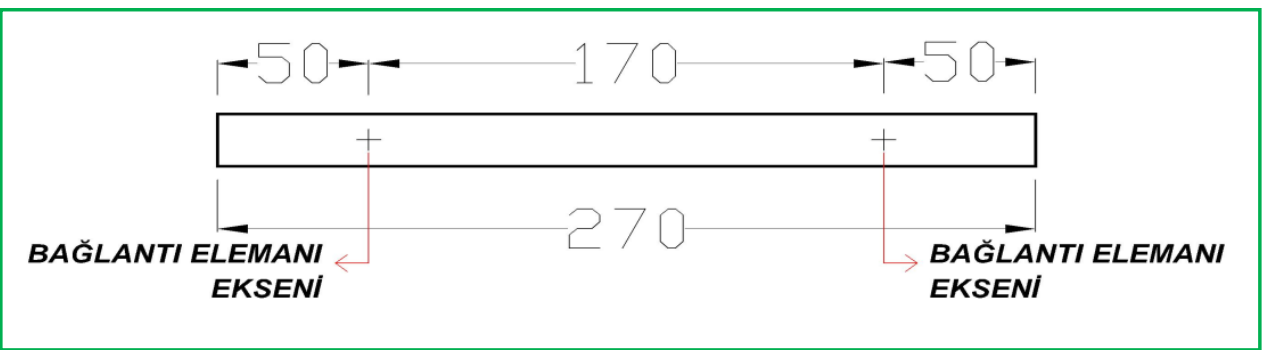

(b)

Şekil 5Deney Örneklerinin genel görünüşü (a) ve (b) birleştirme arakesit yüzeyi (mm).

Deneylerde 2 malzeme çeşidi sentetik reçinelerle kaplanmış YL-Lam ve MDF-Lam, 4 farkıı bağlantı elemanı (Metal T Bağlantı, Plastik T Bağlantı, Ay bağlantı ve Metal L Bağlantı), 2 yükleme tipi ve her örnekten 10 yineleme olmak üzere 160 adet $(2 \times 4 \times 2 \times 10=160)$ deney örneği hazırlanmıştır. Deney örnekleri deneyden önce $20 \pm 2{ }^{\circ} \mathrm{C}$ ve $\% 65 \pm 5$ bağıl nem koşullarındaki iklimlendirme dolabında, denge rutubetine ulaşıncaya kadar bekletilmiştir.

\section{Yöntem}

Deneyler, Karabük Üniversitesi Safranbolu Meslek Yüksekokulu Mobilya ve Dekorasyon Eğitimi Bölümü Test Laboratuarındaki5 KN (Kilo Newton) yük kapasiteli üniversal test cihazında çekme ve basma hızı $5 \mathrm{~mm} /$ dak ve $20 \pm 2{ }^{\circ} \mathrm{C}$ sıcaklığında statik yüklemeler uygulanmıştır. Moment kolları dik üçgen bağlantısından yararlanılarak çekme için $L c ̧=0,08061 \mathrm{~m}$, basma için $\mathrm{Lb}=0,0933 \mathrm{~m}$ olarak hesaplanmıştır. Birleştirmelerin performansı, deney yükleri ve koşulları altında taşınan momentler olarak alınmış ve her bir örnek tarafından diyagonal çekme ve basma yükleri altında taşınan momentler hesaplanmıştır. Diyagonal çekme ve basma deneyinde yükleme şekli ve deney düzenekleri Şekil 6'da gösterilmiştir.

Diyagonal çekme deneylerinde Moment (Mç) aşağıdaki formül ile hesaplanmıştır.

$M c ̧=0.5 F_{\text {maxck }} \times 0.5 \mathrm{Lç}(\mathrm{Nm})$

Burada; Mç= Moment (Nm), $F_{\max }=$ Maks. kuvvet (N), Lç= Moment kolu $(80.61 \mathrm{~mm}$ ).

Diyagonal basınç deneylerinde moment (Mç), aşă̆ıdaki formül ile hesaplanmıştır. 
$\mathrm{M}_{\mathrm{b}}=\mathrm{F}_{\operatorname{maxb}} \times\left[\mathrm{V}\left(150 \overline{\left.)^{2}-(0,5 \mathrm{Lb})^{2}-\mathrm{a}\right](\mathrm{Nm})}\right.\right.$

Burada; $F_{\max }=$ Maks. kuvvet, $M_{b}=$ Basınç kuvveti altında taşınan moment (N.m),

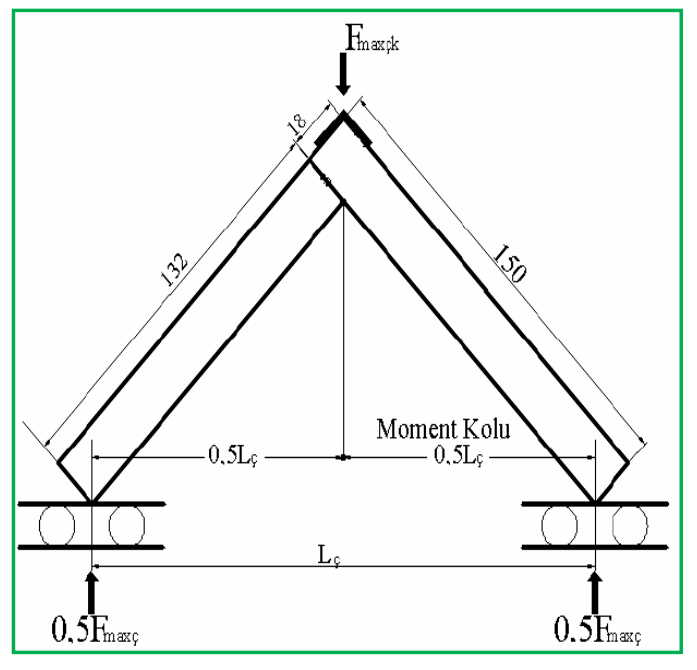

$F_{\operatorname{maxb}}=$ maksimum kuvvet $(\mathrm{N}), \mathrm{L}_{b}=$ Moment kolu (93.34 $\mathrm{mm}) \mathrm{a}=12.73 \mathrm{~mm}^{\prime} \mathrm{dir}$

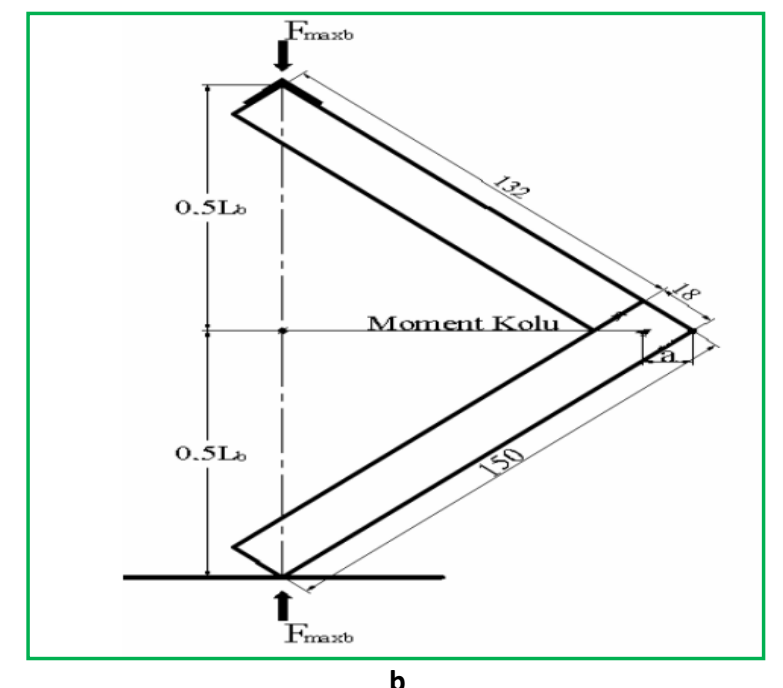

Şekil 6 Diyagonal çekme (a) ve basma (b) deney düzeneği ve yük uygulama biçimi (mm).

\section{İstatistiksel değerlendirme}

Basma ve çekme yükleri altında taşınan moment kapasitelerinde, malzeme çeşidi ve bağlantı elemanın etkilerini belirlemek amacıyla çoklu varyans analizi kullanılmıştır. Varyans kaynaklarının karşılıklı etkileşimlerinin $(p<0.05)$ olarak anlamlı çıkması halinde, farklılıkların hangi faktör için önemli olduğu Duncan testi ile belirlenmiştir.

\section{BULGULAR}

Ahşap esaslı levhalardan (MDF-Lam, YL-Lam) ile metal T, plastik $T$, metal $L$ ve Ay bağlantı elemanları kullanarak hazırlanan $\mathrm{L}$ tipi köşe birleştirme deney örneklerinin diyagonal çekme ve basma deneyleri sonucunda elde edilen moment taşıma kapasitesi değerleri Çizelge 2'de, verilmiştir.

Çizelge 2 Diyagonal çekme ve basma deneyleri sonucu elde edilen moment taşıma kapasiteleri.

\begin{tabular}{|c|c|c|c|c|c|c|c|c|}
\hline \multirow[t]{5}{*}{ Bağlantı Elemanı Çeşidi } & \multicolumn{8}{|c|}{ Moment Taşıma Kapasitesi (N.m) } \\
\hline & \multicolumn{4}{|c|}{ Diyagonal Çekme } & \multicolumn{4}{|c|}{ Diyagonal Basma } \\
\hline & \multicolumn{8}{|c|}{ Malzeme Türü } \\
\hline & \multicolumn{2}{|c|}{ YL-Lam } & \multicolumn{2}{|c|}{ MDF-Lam } & \multicolumn{2}{|c|}{ YL-Lam } & \multicolumn{2}{|c|}{ MDF-Lam } \\
\hline & $\mathrm{X}_{\text {ort. }}$ & Std. & $\mathrm{X}_{\text {ort. }}$ & Std. & Xort. & Std. & Xort. & Std. \\
\hline Metal T Bağlantı & 69.15 & 10.44 & 109.40 & 27.35 & 35.07 & 2.21 & 48.25 & 2.81 \\
\hline Plastik T Bağlantı & 65.84 & 11.55 & 108.48 & 33.08 & 27.22 & 5.14 & 39.97 & 5.73 \\
\hline Ay Bağlantı & 47.13 & 8.20 & 60.19 & 13.23 & 25.62 & 4.24 & 35.18 & 1.58 \\
\hline \multirow[t]{2}{*}{ Metal L Bağlantı } & 69.95 & 13.65 & 118.89 & 29.03 & 25.18 & 3.65 & 48.98 & 2.75 \\
\hline & & & \multicolumn{4}{|c|}{$X_{\text {ort. }}$ Ortalama Değer } & \multicolumn{2}{|c|}{ Std: Standart Sapma } \\
\hline
\end{tabular}

Çizelge 2 incelendiğinde, L tipi köşe birleştirmelerinde malzeme türü ve bağlantı elemanı çeşidine ilişkin ortalama diyagonal çekme eğilme moment değeri, en yüksek değer MDF-Lam malzemesi ile metal $L$ bağlantı elemanı ile hazırlanan (118.89 N.m) örneklerde, en düşük değer ise YL-Lam malzemesi ile ay bağlantı elemanı ile hazırlanan (47.13 N.m) örneklerde bulunmuştur.
Diyagonal basma eğilme moment değeri, en yüksek en yüksek sentetik reçinelerle kaplanmış (MDF-Lam) da metal L bağlantı elemanında (48.98 N.m), en düşük sentetik reçinelerle kaplanmış yonga levha (YL-Lam) da metal L bağlantı elemanında (25.18 N.m) bulunmuştur. Malzeme türü ve bağlantı elemanı çeşidinin, "L" tipi köşe birleştirmelerinin moment taşıma kapasitesi üzerindeki etkilerine ilişkin çoklu varyans analizleri sonuçları Çizelge 3'de verilmiştir. 
Çizelge 3. Çoklu varyans analizi sonuçları.

\begin{tabular}{|c|c|c|c|c|c|c|}
\hline \multirow{6}{*}{ 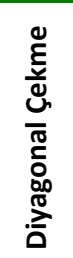 } & Varyans Kaynakları & Kareler Toplamı & Serbestlik Derecesi & $\begin{array}{l}\text { Kareler } \\
\text { Ortalaması }\end{array}$ & F Değeri & $\begin{array}{l}\text { Hata Ihtimali } \\
P<0.05\end{array}$ \\
\hline & Malzeme Türü & 26246.099 & 1 & 26246.099 & 62.560 & 0.000 \\
\hline & Bağlantı Elemanı Çeşidi & 20679.112 & 3 & 6893.037 & 16.430 & 0.000 \\
\hline & $\mathrm{MÇ} \times \mathrm{BE}$ & 3778.086 & 3 & 1259.362 & 3.002 & 0.036 \\
\hline & Hata & 30206.588 & 72 & 419.536 & & \\
\hline & Toplam & 607464.678 & 80 & & & \\
\hline \multirow{5}{*}{ 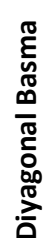 } & Malzeme Türü & 1931.596 & 1 & 1931.596 & 136.292 & 0.000 \\
\hline & Bağlantı Elemanı Çeşidi & 3373.767 & 3 & 1124.589 & 79.360 & 0.000 \\
\hline & $\mathrm{MÇ} \times \mathrm{BE}$ & 1809.534 & 3 & 603.178 & 42.560 & 0.000 \\
\hline & Hata & 1020.421 & 72 & 14.173 & & \\
\hline & Toplam & 96233.528 & 80 & & & ntıFlemanı Cesidi \\
\hline
\end{tabular}

Malzeme türü, bağlantı elemanı çeşidi ve malzeme türübağlantı elemanı çeşidi etkileşimlerinin (MÇ x BE) "L" tipi demonte mobilya köşe birleştirmelerinin hem çekme ve hem de basma yükü altındaki moment taşıma kapasitesi değerleri üzerindeki 0.05 hata payı ile istatistiksel olarak anlamlı bulunmuştur. Malzeme türüne göre moment taşıma kapasitesi değerlerine ilişkin karşılaştırma sonuçları Çizelge 4'de verilmiştir. Çizelge 4'e göre, $L$ tipi köşe birleştirmelerinde malzeme türüne ilişkin ortalama diyagonal çekme eğilme moment değeri, en yüksek sentetik reçinelerle kaplanmış (MDF-Lam) da (99.24 N.m), en düşük sentetik reçinelerle kaplanmış yonga levha (YLLam) da (63.02 N.m), MDF-Lam deney örnekleri YL-Lam deney örneklerine göre \%36.5 daha başarılıdır. Diyagonal basma eğilme moment değeri, en yüksek sentetik reçinelerle kaplanmış (MDF-Lam) da (38.40 N.m), en düşük sentetik reçinelerle kaplanmış yonga levha (YLLam) da (28.17 N.m), MDF-Lam deney örnekleri YL-Lam deney örneklerine göre \%26.4 daha başarılı olduğu tespit edilmiştir.

Çizelge 4 Malzeme türüne göre moment taşıma kapasiteleri ve homojenlik grupları.

\begin{tabular}{lcclcc}
\hline \multicolumn{5}{c}{ Moment Taşıma Kapasitesi (N.m) } \\
\hline \multicolumn{3}{c}{ Diyagonal Çekme } & \multicolumn{4}{c}{ Diyagonal Basma } \\
Malzeme Türü & Oort. $_{\text {ory }}$ & HG & Malzeme Türü & Xort. $^{\text {HG }}$ \\
MDF-Lam & 99.24 & A & MDF-LAM & 38.40 & A \\
YL-Lam & 63.02 & B & YLAM & 28.27 & B \\
& & & & HG: Homojenlik & Grup \\
\hline
\end{tabular}

Çizelge 5 incelendiğinde, bağlantı elemanı çeşidine ilişkin ortalama diyagonal çekme eğilme moment değeri, en yüksek metal L bağlantı elemanında (94.42 N.m), en düşük ise ay bağlantı elemanında (53.66 N.m), metal L bağlantı elemanı ile hazırlanan deney örnekleri ay bağlantı elemanı ile hazırlanan deney örneklerine göre \%43.2 daha fazla olduğu belirlenmiştir. Diyagonal basma eğilme moment değeri, en yüksek metal $T$ bağlantı elemanında (41.66 N.m), en düşük ise ay bağlantı elemanında (25.40 N.m), metal T bağlantı elemanı ile hazırlanan deney örnekleri ay bağlantı elemanı ile hazırlanan deney örneklerine göre \%39 daha başarılı sonuç elde edilmiştir.

Çizelge 5Bağlantı elemanı çeşidine göre moment taşıma kapasiteleri ve homojenlik grupları.

\begin{tabular}{lcccccc}
\hline \multicolumn{5}{c}{ Moment Taşıma Kapasitesi (N.m) } \\
\cline { 1 - 5 } Bağlantı Elemanı I & X $_{\text {ort. }}$ & HG & Bağlantı Elemanı & X $_{\text {ort. }}$ & HG \\
Metal L Bağlantı & 94.42 & A & Metal T Bağlantı & 41.66 & A \\
Metal T Bağlantı & 89.28 & A & Metal L Bağlantı & 37.08 & B \\
Plastik T Bağlantı & 87.16 & A & Plastik T Bağlantı & 28.60 & C \\
Ay Bağlantı & 53.66 & B & Ay Bağlantı & 25.40 & D \\
& & \multicolumn{4}{c}{ HG: Homojenlik Grup } \\
\hline
\end{tabular}

Çizelge 6'ya göre, L tipi köşe birleştirmelerinde malzeme türü-bağlantı elemanı çeşidi ikili etkileşimine ilişkin ortalama diyagonal basma eğilme moment değeri, en yüksek en yüksek sentetik reçinelerle kaplanmış (MDFLam) ile metal L bağlantı elemanında (48.98 N.m), en düşük sentetik reçinelerle kaplanmış yonga levha (YLLam) da metal L bağlantı elemanında (25.18 N.m) bulunmuştur. MDF-Lam ile metal $L$ bağlantı elemanları kullanılarak hazırlanan deney örnekleri, YL-Lam ile metal $\mathrm{T}$ bağlantı elemanları kullanılarak hazırlanan deney örneklerine göre \%95 daha başarılı olduğu tespit edilmiştir. 
Çizelge 6Malzeme türü-bağlantı elemanı çeşidi ikili etkileşimine göre moment taşıma kapasiteleri ve homojenlik grupları.

\begin{tabular}{lccc} 
& Moment Taşıma Kapasitesi (N.m) & \\
\hline \\
Malzeme Çeşidi & Diyagonal Basma & Xort. & HG \\
MDF-Lam & Bağlantı Elemanı & 48.98 & 48.25 \\
& Metal L Bağlantı & 39.97 & A \\
& Metal T Bağlantı & 35.18 & 35.07 \\
YL-Lam & Plastik T Bağlantı & 27.22 & B \\
& Ay Bağlantı & 25.62 & C \\
& Metal T Bağlantı & C & C \\
& Plastik T Bağlantı & C Bağlantı & HG: Homojenlik Grup
\end{tabular}

\section{Deformasyon Tipleri}

YL-Lam metal $T$, Plastik $T$, Metal $L$ ve Ay bağlantı birleştirme elemanı ile birleştirlen örneklerin diyagonal çekme deneyinde, Şekil 7'deki gibi deformasyonlar görülmüştür. Birleştirme elemanlarında herhangi bir deformasyon mevcut oluşmamış iken, montajı için kullanılan vidalarda eğilmeler görülmüştür. YL-Lam levhanın kenar(köşe) noktalarında çekme kuvetinin yaptığı etki ile kırılmalar meydana gelmiştir. Metal T, Plastik T ve Ay bağlantı birleştirme elemanı kullanılarak

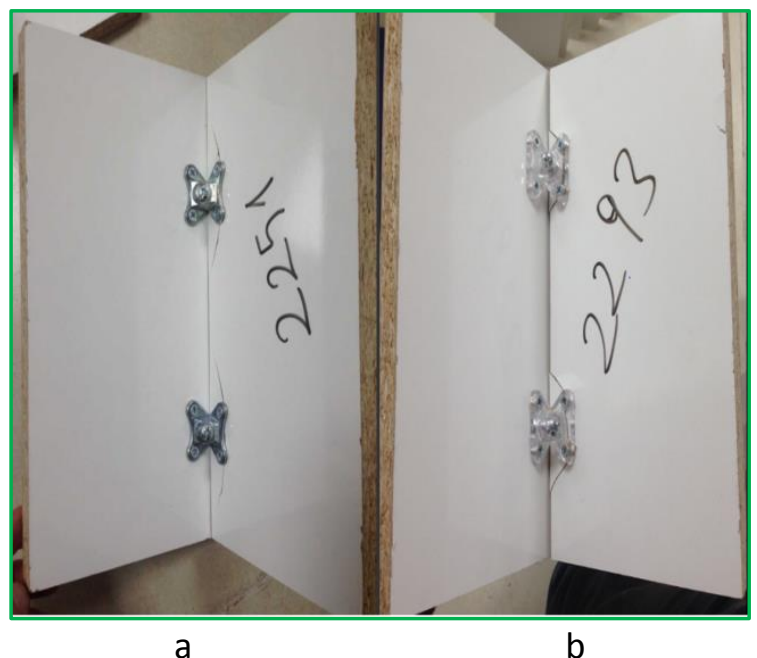

birleştirilecek mobilya elemanların kenar paylarını artırmak süretiyle kenarlarda oluşacak deformasyonların önlenebileceği düşünülmektedir. Metal $L$ ile birleştirlen YL-Lamda birleştirme elemanı ve montaj elemanında(vida) eğilmeler ile birlikte montaj elemanın çekme etkisinde yapmış olduğu deformasyonlar mevcuttur. Montaj elemanın deformasyonunu önlemek amacıyla kılavuz amaçlı ve yonga levha ile uyum sağlayacak üçüncü bir elemanın kullanılması önerilebilir.

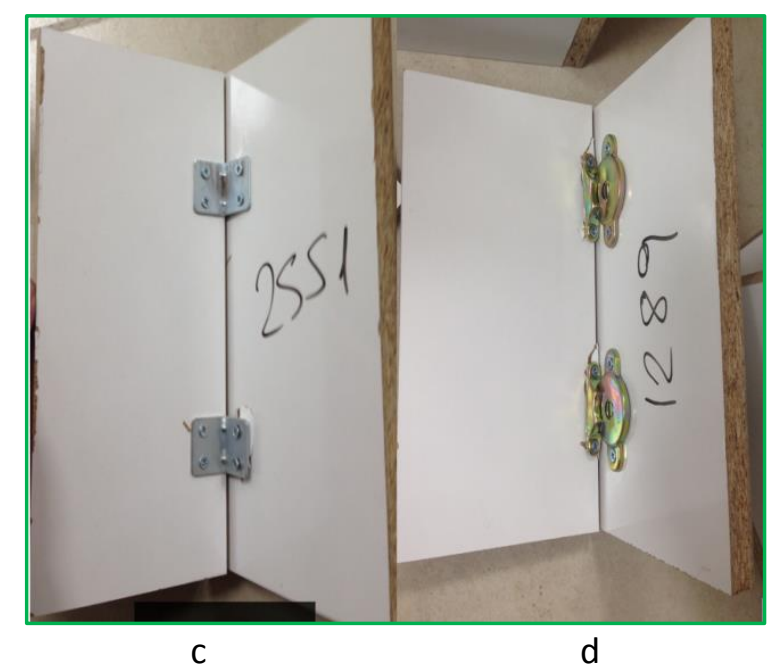

Şekil7 Metal T (a), Plastik T (b), Metal L (c),Ay bağlantı (d) birleştirmelerinde meydana gelen deformasyon tipleri.

MDF-Lam levhanın metal T, Plastik T, Metal L ve Ay bağlantı birleştirme elemanı ile birleştirlen örneklerin diyagonal çekme deneyinde, Şekil 8'deki gibi deformasyonlar görülmüştür. Birleştirme elemanlarında herhangi bir deformasyon mevcut oluşmamış iken, montajı için kullanılan vidalarda eğilmeler görülmüştür. MDF-Lam levhanın kenar(köşe) noktalarında çekme kuvvetinin yaptığı etki ile kırılmalar meydana gelmiştir. Plastik T ve ay bağlantı birleştirme elemanı kullanılarak birleştirilecek mobilya elemanların kenar paylarını artırmak suretiyle kenarlarda oluşacak deformasyonların önlenebileceği düşünülmektedir. Metal $L$ ile birleştirilen MDF-Lam da birleştirme elemanı ve montaj elemanında(vida) eğilmeler ile birlikte montaj elemanın çekme etkisinde yapmış olduğu deformasyonlar mevcuttur. Ay bağlantı elemanı ile birleştirilen MDF-Lam levhanın kenarında kırılmalar, ay bağlantı elemanında eğilmeler ve montaj elemanı olarak kullanılan vidanın basma etkisi ile oluşturduğu deformasyonlar görülmüştür. 


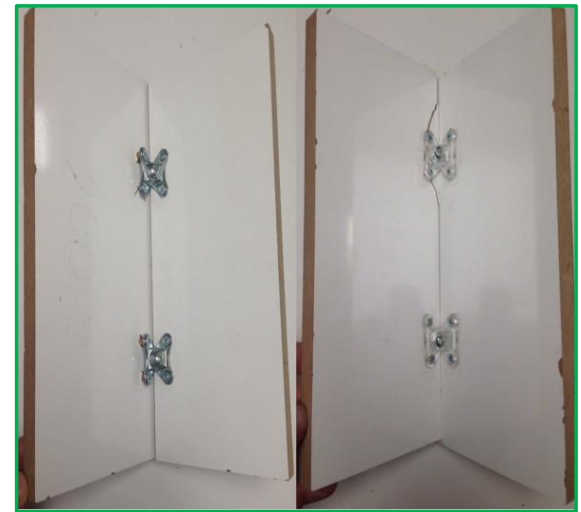

a

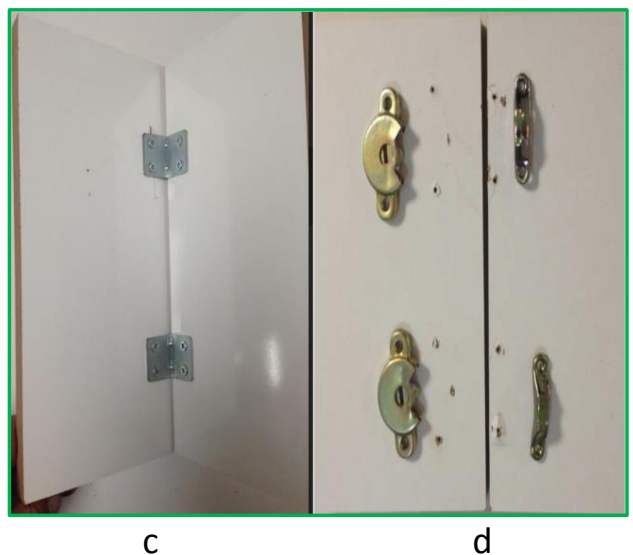

Şekil 8. Metal T (a), Plastik T (b), Metal L (c), ve Ay bağlantı (d)birleştirmelerde meydana gelen deformasyon tipleri.

YL-Lam levhanın metal T, Plastik T, Metal L ve Ay bağlantı birleştirme elemanı ile birleştirilen örneklerin diyagonal basma deneyinde, Şekil 9'daki gibi deformasyonlar görülmüştür. Metal $T$ tipi birleştirme elemanı ile hazırlanan YL-Lam levha örneklerinde bağlantı elemanında kırıma ve montaj elemanı olarak kullanılan vidanın YL-Lam içerisinde çekilmesi ile oluşan deformasyonlar görülmüştür. Plastik $T$ tipi birleştirme elemanı ile hazırlanan yonga levha örneklerinde montaj elemanı olarak kullanılan vidanın YL-Lam içerisinde çekilmesi ile oluşan ve bağlantı elemanın basma etkisi yaptığı deformasyonlar mevcuttur. Metal L tipi birleştirme elemanı ile hazırlanan YL-Lam örneklerinde bağlantı elemanında eğilme ve montaj elemanı olarak kullanılan vidanın YL-Lam içerisinde çekilmesi ile oluşan deformasyonlar mevcuttur. Ay bağlantı elemanı ile birleştirilen YL-Lam örneklerin kenarında kırılmalar, ay bağlantı elemanında eğilmeler ve montaj elemanı olarak kullanılan vidanın basma etkisi ile oluşturduğu deformasyonlar görülmüştür.

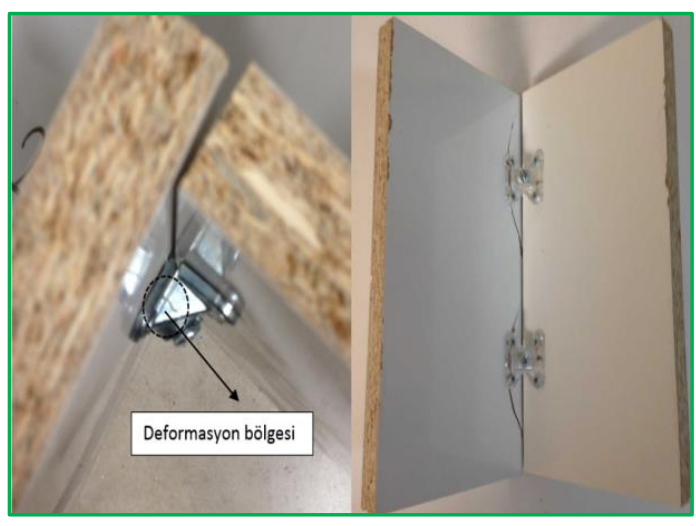

a

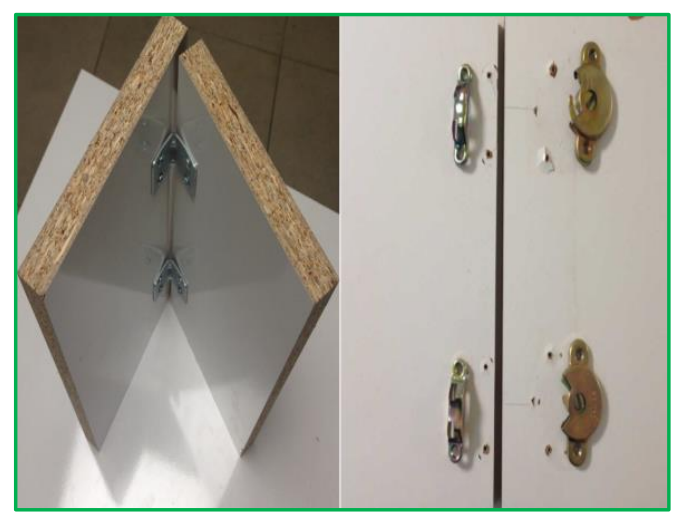

C

d

Şekil 9. Metal T (a), Plastik T (b), Metal L (c), ve Ay bağlantı (d) birleştirmelerde meydana gelen deformasyon tipleri.

MDF-Lam levhanın metal T, Plastik T, Metal L ve Ay bağlantı birleştirme elemanı ile birleştirilen örneklerin diyagonal basma deneyinde, Şekil 10'daki gibi deformasyonlar görülmüştür. Metal T tipi birleştirme elemanı ile hazırlanan MDF-Lam örneklerinde bağlantı elemanında kırılma ve montaj elemanı olarak kullanılan vidanın MDF-Lam içerisinde çekilmesi ile oluşan deformasyonlar görülmüştür. Plastik $T$ tipi birleştirme elemanı ile hazırlanan lif levha örneklerinde montaj elemanı olarak kullanılan vidanın MDF-Lam içerisinde çekilmesi ile oluşan deformasyonlar mevcuttur. Metal L tipi birleştirme elemanı ile hazırlanan MDF-Lam örneklerin bağlantı elemanında eğilme ve montaj elemanı olarak kullanılan vidanın MDF-Lam içerisinde çekilmesi ile oluşan deformasyonlar mevcuttur. Ay bağlantı elemanı ile birleştirilen MDF-Lam örneklerin kenarında kırılmalar, ay bağlantı elemanında eğilmeler ve montaj elemanı olarak kullanılan vidanın basma etkisi ile oluşturduğu deformasyonlar görülmüştür. 

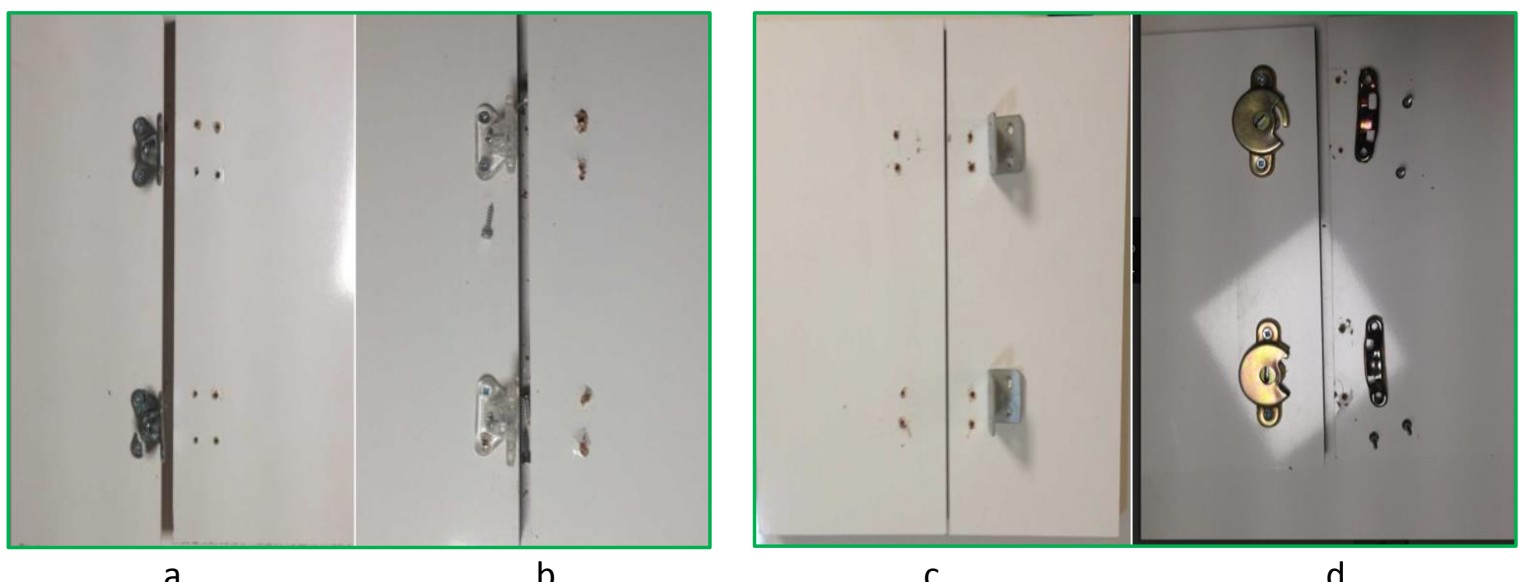

Şekil 10. Metal T (a), Plastik T (b), Metal L (c), ve Ay bağlantı (d) birleştirmelerde meydana gelen deformasyon tipleri.

\section{SONUÇ VE TARTIŞMA}

Bu çalışmada, ahşap esaslı malzemelerden (MDF-Lam, YLLam) ile demonte tipi bağlantı elemanları kullanılarak hazırlanan L tipi köşe birleştirmelerin diyagonal çekme ve basma deneyleri sonucu elde edilen eğilme moment değerleri araştırılmıştır.

Malzeme türüne göre diyagonal çekme ve basma yüklemeleri altında taşınan ortalama eğilme moment değeri en yüksek MDF-Lam'da, en düşük ise YL-Lam'da bulunmuştur. MDF-Lam levhanın YL-Lam levhaya göre daha başarıı olması, yapısal özelliklerinden kaynaklanmış olabilir. Özgül ağırlığının daha yüksek olması ve moleküller arasındaki kohezyon kuvvetinin daha kuvvetli olması nedeniyle, MDF-Lam levhanın mekanik özellikleri YL-Lam levhadan daha iyidir. Yapılan çalışmalar yapmış olduğumuz çalışma ile paralellik göstermektedir. Literatürde kutu konstrüksiyonlu mobilya üretiminde kullanılan köşe birleştirmelerden tutkalsız (demonte) birleştirmelerin çekme ve basma direnci üzerine birçok çalışmada lif levhalar, yonga levhalardan daha iyi sonuçlar vermişlerdir (Efe 1994; Örs ve Efe 1996; Örs ve Efe 1998; Kasal 1998; Efe 1999; Efe ve Kasal 2000a; Efe ve Kasal 2000b; İmirzi 2000; Şafak 2000; Efe 2001; Efe ve İmirzi 2001; Efe vd. 2002; Efe vd. 2003; Kasal vd. 2006, Şakacı 2010; Tüfekli 2010; Efe vd. 2012).

Bağlantı elemanı çeşidi bakımından; diyagonal çekme yüklemeleri altında taşınan ortalama eğilme moment değeri sırasıyla metal $L$ bağlantı, metal $T$ bağlantı, plastik $T$ bağlantı ve ay bağlantı elemanlarında olduğu belirlenmiştir. Diyagonal basma yüklemeleri altında taşınan ortalama eğilme moment değeri ise sırasıyla metal $T$ bağlantı, metal $L$ bağlantı, plastik $T$ bağlantı ve ay bağlantı elemanlarında olduğu tespit edilmiştir. Güray (2002) yapmış araştırmada, minifiks, kavela ve farklı köşe birleştirme tiplerinin diyagonal çekme direnci üzerine etkilerini araştırmışlardır. En yüksek diyagonal çekme direncini, MDF-Lam levha ile alyans vidalı birleştirmelerden elde ettiği sonuçlar ile yapmış olduğumuz çalışma sonuçları benzer niteliktedir.

Malzeme türü ve bağlantı elamanı çeşidi etkileşimi bakımından; diyagonal çekme yüklemeleri altında taşınan ortalama en yüksek eğilme moment değeri MDF-Lam ile metal L bağlantı elemanı kullanılarak hazırlanan deney örneklerinde, en düşük eğilme moment değeri ise YL-Lam ile ay bağlantı elemanı kullanılarak hazırlanan deney örneklerinde belirlenmiştir. Diyagonal basma yüklemeleri altında taşınan ortalama en yüksek eğilme moment değeri MDF-Lam ile metal T bağlantı elemanı kullanılarak hazırlanan deney örneklerinde, en düşük eğilme moment değeri ise YL-Lam ile ay bağlantı elemanı kullanılarak hazırlanan deney örneklerinde bulunmuştur.

$\mathrm{Bu}$ sonuçlara göre; kutu konstrüksiyonlu mobilya tasarımında, malzeme acısından ekonomik kriterler de dikkate alınarak malzeme tercihi, MDF-Lam, bağlantı elemanı tercihi ise metal $T$ bağlantı ve metal $L$ bağlantı elemanı tercih edilebilir.

\section{KAYNAKLAR}

Altınok M (1998) Masa yapımında uygulanan sütun ayaklarda konstrüksiyon modellemesi. Gazi Üniversitesi Politeknik Dergisi, 1(1-2):105-109. 
Demirci S, Efe H, Kasal A, İmirzi HÖ, Özen E (2011) Çeşitli bağlantı elemanları ile üretilen " $\mathrm{L}$ " tipi demonte mobilya köse birleştirmelerinin moment kapasitesi. Kastamonu Üniversitesi Orman Fakültesi Dergisi, 11(2):138- 145.

Efe H (1994) Modern mobilya çerçeve konstrüksiyon tasarımında geleneksel ve alternatif bağlantı tekniklerinin mekanik davranış özellikleri. K.T.Ü. Fen Bilimleri Enstitüsü Doktora Tezi, Trabzon,

Efe H (1999) Kutu konstrüksiyonlu mobilyada sabit (yabancı çıtalı) ve demonte (trapez) köşe birleştirmelerin çekme ve basma dirençleri. Gazi Üniversitesi Politeknik Dergisi, 2(4):43-51.

Efe H, Kasal A (2000a) Kutu konstrüksiyonlu sabit ve demonte mobilya köşe birleştirmelerde çekme direnci. Gazi Üniversitesi Endüstriyel Sanatlar Eğitim Fakültesi Dergisi, 8(8):61-74.

Efe H, Kasal A (2000b) Tabla tipi mobilya köşe birleştirmelerinde eğilme direnci özellikleri. Z.K.Ü. Karabük Teknik Eğitim Fakültesi Teknoloji Dergisi, 3(4):33- 45.

Efe H, İmirzi HÖ (2001) Çerçeve konstrüksiyonlu masif mobilya "T" birleştirmelerde çekme dirençleri karşılaştırmaları. Gazi Üniversitesi Politeknik Dergisi, 4(4):905-101.

Efe H (2001) Kutu konstrüksiyonlu mobilyada sabit (yabancı çıtalı) ve demonte (trapez) köse birleştirmelerde çekme ve basma dirençleri. Gazi Üniversitesi Politeknik Dergisi, 4(4):17.

Efe H, Kasal A, Gürleyen L (2002) Çeşitli tutkallarla yapıştırılmış kutu konstrüksiyonlu kavelalı köşe birleştirmelerin basma direnci etkisi. Gazi Üniversitesi Endüstriyel Sanatlar Eğitim Fakültesi, 10:39-56.

Efe H, Kasal A, Diler H (2003) Kutu konstrüksiyonlu vidalı mobilya köşe birleştirmelerde eğilme moment dirençleri. Afyon Kocatepe Üniversitesi Fen Bilimleri Dergisi, 6(1):97-110.

Efe H, Kasal A, Çağatay K, Kuşkun T (2012) Ahşap boy birleştirmelerde farklı bağlantı tekniklerinin çekme mukavemetlerinin karşılaştırııması. Kastamonu Üniversitesi Orman Fakültesi Dergisi, 12(1):80-89.

Güray A, Kılıç M, Özyurt A (2002) Mobilya köşe birleştirmelerinde kullanılan farklı birleştirme elemanlarının diyagonal çekme direnci üzerine etkilerinin araştırıması. Pamukkale Üniversitesi Mühendislik Fakültesi Mühendislik Bilimleri Dergisi, 8(1):131-137.

Hayashi Y, Eckelman AC (1986) Design of corner block with anchor bolt table joints, Forest Products Journal, 36(2):44-48.

İmirzi HÖ (2000) Çerçeve konstrüksiyonlu masif mobilya " $T$ " birleştirmelerinin mekanik özellikleri, Gazi Üniversitesi Fen Bilimleri Enstitüsü Yüksek Lisans Tezi, Ankara, $49 \mathrm{~s}$.

Karabulut S (2010) Mobilya köşe birleştirmelerinde kullanılan farklı bağlantı elemanlarının sonlu elemanlar metodu ile mukavemet analizi. Karabük Üniversitesi Fen Bilimleri Enstitüsü Yüksek Lisans Tezi, Karabük, 68 s.
Kasal A (1998) Mobilya masa ayak- kayıt birleştirmelerde köşe takozunun birleştirme mukavemetine etkileri. Gazi Üniversitesi Fen Bilimleri Enstitüsü Yüksek Lisans Tezi, Ankara, $67 \mathrm{~s}$.

Kasal A, Şener S, Belgin MÇ, Efe H (2006) Bending strength of screwed corner joints with different materials. Gazi Üniversitesi Fen Bilimleri Dergisi, 19(3):155-161.

Kasal A, Erdil YZ, Zhang JL, Efe H, AvcI E (2008) Estimation equations for moment resistances of L-type screw corner joints in case goods furniture. Forest Product Journal, 58(9):21-27.

Kasal A (2008) Effect of the number of the screws and scriw size on moment capacity of furniture corner joints in case construction. Forest Product Journal, 58(6):36-44.

Kılıçalp H (2008) kutu mobilyalarda kullanılan bazı modüler bağlantı elemanlarının direnç özelliklerinin belirlenmesi. ZKÜ Fen Bilimleri Enstitüsü Bilim Uzmanlığı Tezi, Karabük, $93 \mathrm{~s}$.

Örs Y, Efe H (1998) Mobilya (çerçeve konstrüksiyon) tasarımında bağlantı elemanlarııın mekanik davranış özellikleri. Doğa-TR J. Of Agriculture AndForestry, 22(5):21-27.

Örs Y, Efe H, Kasal A (2001) Kutu konstrüksiyonlu vidalı mobilya köşe birleştirmelerinde çekme direnci. Gazi Üniversitesi Politeknik Dergisi, 4(4):1-9.

Özçifçi A, Kılıçalp H, Toker H (2008) Kutu mobilyalarda kullanılan bazı modüler bağlantı elemanlarının direnç özelliklerinin belirlenmesi. Karabük Üniversitesi Teknoloji Dergisi, 11(1):45-57.

Smardzweski J, Prekrad S (2002) Stress distribution in disconnected furniture joints. Electronic Journal of Polish Agricultural Universities Wood Techology, 36:173-183.

Şafak R (2000) Kutu konstrüksiyonlu mobilya köşe birleştirmelerinde mekanik özellikler. Gazi Üniversitesi Fen Bilimleri Enstitüsü Yüksek Lisans Tezi, Ankara, $47 \mathrm{~s}$.

Şakacı D (2010) Mobilya üretiminde kullanılan plastik esaslı levhanın çeşitli köşe birleştirmelerinin diyagonal basma ve çekme performansına etkileri. Gazi Üniversitesi Fen Bilimleri Enstitüsü Yüksek Lisans Tezi, Ankara, $76 \mathrm{~s}$.

Tankut N (2006) Moment resistance of corner joints connected with different RTA fasteners in cabinet construction. Forest Products Journal, 56:35-40.

Tüfekli Y(2010) Petek dolgulu levhalar ve farklı yapım teknikleri ile üretilmiş kutu mobilya "L" tipi köse birleştirmelerinin moment tasıma kapasitelerinin belirlenmesi. Gazi Üniversitesi Fen Bilimleri Enstitüsü Yüksek Lisans Tezi, Ankara, $59 \mathrm{~s}$.

Taştekin A, Özyurt A (2001) minifixli köşe birleştirmelerin dayanım özelliklerinin araştırıması ve alternatif birleştirmelerle karşılaştırılması. H. Ü. M. T. Y. O. AEM Bölümü Lisans Bitirme Tezi, Ankara.

Trinka M (1989) Ready-to-assemble furniture; marketing and material use trends. Forest Products Journal, 40(3):35-39. 